the intermediate state appears to be more fruitful in the rationalization of observed effects of configuration on reactivity than are similar considerations based on the conformation of the reactant in the ground state.

'The use of proton magnetic resonance spectroscopy for establishing the conformations of sugar acetates was briefly discussed.

The symposium altogether was a lively and stimulating affair, and in the closing remarks the chairman commented on the increasing importance of applications of these newer interpretations of carbohydrate reactions in the ever-widening field of biochemistry.

\section{ASSOCIATION OF SCHOOL NATURAL HISTORY SOCIETIES \\ EIGHTH ANNUAL EXHIBITION, 1956}

$\mathrm{T}$

HE eighth annual exhibition of the Association of School Natural History Societies was held at the British Museum (Natural History) on October 20. Mr. Eric Hosking, who is a founder-member of the Association, gave a lecture on "Birds in Action" before an audience of 150 children. This was illustrated by a selection of magnificent photographs of birds, for which Mr. Hosking is rightly famous. By means of electronic flash and occasionally with the uso of a specially designed photo-electric camera release, some remarkable pictures had been obtained.

After the lecture, the exhibition was opened to members and to the public. A notable feature of this year's exhibition was the reduction in the number of charts and diagrams coupled with an increase in live exhibits. While it is true that the tabulation of results and their presentation in graphic form is an admirable, if not essential, way of summarizing field work, it is also true that this practice often makes a dull exhibit. Nine out of the twelve items displayed by Bishop's Stortford College were living exhibits, including an elaborate reconstruction of a portion of a refuse dump. In another exhibit were specimens of the white-lipped hedge snail (Cepea nemoralis), showing the many variants of shell-marking. African clawed frogs, reared at the school, made an interesting contrast to familiar British amphibians. Other examples of living freshwater animals were shown by Oundle School, Felsted School and Lord Wandsworth College, Hants. The latter school displayed also a home-made portable instrument for the field measurement of salinity in salt marshes. This operated by measuring the electrical conductivity of the water contained in a long polythene tube. The study of the natural history of mammals is a subject which has been sadly neglected by the majority of naturalists. It was therefore encouraging to see that Kimbolton School, Hunts, had begun a scheme of trapping and marking small mammals. A number of living small rodents was displayed.

Marine studies had been undertaken by Dulwich College, which displayed a large collection of marine algae and a shore transect illustrating the zonation of these species on the sea-shore. Similar work was described by Ackworth School, Yorkshire.

A pupil of Bishop's Stortford College had prepared a model to illustrate the trapping of moths at a mercury-vapour light trap. A relief model of an area of countryside, above which bird flight-lines were indicated, showed that whereas some species of bird preferred to fly along the valleys, other species tended to fly in a direction perpendicular to the contour lines. Limehurst Natural History Society (Garendon School, Loughborough, Leics.) displayed models, photographs and charts which described their island nature reserve and the wild life found there.

Lepidoptera were not so prominent in the exhibition as they were last year. Several schools showed a few in connexion with their other exhibits, but the collection shown by Tonbridge School was the most comprehensive.

Geology was represented by a soil profile across an area of poor fen, exhibited by Cranbrook School, and a selection of rock samples and fossils from an ironstone cutting brought by Uppingham School. Also included in their exhibits were owl pellets and kestrel pellets, whole and dissected. Owl pellets were featured in the displays by Oundle School, and the William Grimshaw School, London. The latter school had prepared a complete demonstration of the various stages in the dissection of a pellet, culminating in the 'reconstruction' of most of the skeleton of an individual vole from bones found in a single pellet.

It was announced that further exhibitions have been arranged in Leicester (November 24) and Leeds (May 11, 1957). Other meetings are being planned to take place in Exeter and Manchester. Further details of these meetings can be obtained from $\mathrm{O}$. N. Bishop, Hon. General Secretary, A.S.N.H.S., 115 Shelly Road, Exmouth, Devon. A special edition of the Exhibition Catalogue is available $(10 \mathrm{~d}$, including postage), which contains a full list of exhibits, a list of members and their addresses, and the annual reports of the committee.

In addition to those displays put on by member schools there were a number of guest exhibitors. The Amateur Entomologists' Society, the Royal Society for the Protection of Birds, the School Nature Study Union and the Universities Federation for Animal Welfare displayed their publications. The Children's Centre showed material illustrating their Saturday morning activities; a scale-model of as small portion of Epping Forest was particularly noteworthy.

\section{O. N. BISHOP}

\section{EXPEDITION TO THE SALMON AND LEDUC GLACIERS}

A $\mathrm{N}$ expodition to the Salmon and Leduc Claciers A was organized in 1956 by the University of Toronto under the leadership of Prof. J. A. Jacobs at the request of the Defence Research Board and the National Research Council of Canada. Eleven men took part, and the expedition lasted from the middle of May until the end of August.

'The Salmon and Leduc Glaciers, which are situated near the coast of British Columbia opposite the southern tip of Alaska (approximately lat. $56^{\circ} 10^{\prime}$ N., long. $130^{\circ} 15^{\prime} \mathrm{W}$.), were chosen since they lie between the glaciers from the Juneau ice field to the north and those of the Washington Cascade and Olympic Mountains to the south, on which a con. siderable amount of work has already been done. The area is also interesting since the Granduc ore body lies in the mountains surrounded by these and other glaciers. 
The objectives of the expedition, which forms part of Canada's glaciological programme in the International Geophysical Year, were two-fold : to train men and test equipment for use on the Canadian expedition to Northern Ellesmere Island next year, and to obtain information about British Columbia glaciers.

'I'he whole area around the Salmon Glacier was surveyed and a map of the glacier and surrounding terrain is being prepared by Mr. K. Arnold. The main part of the programme was given over to extensive seismic and gravity surveys. The seismic programme was organized by Dr. R. R. Doell (Massachusetts Institute of Technology) and Mr. J. R. Weber (University of Alberta). In all, 354 profiles were shot, the work being greatly facilitated by the Granduc Mining Company, which provided air-borne support and the loan of a 'sno-cat' tractor. The depth of ice was generally found to be about onehalf the width of the glacier, amounting to 2,000 $2,400 \mathrm{ft}$.

Dr. F. S. Grant (University of Toronto) organized the gravity work. At first the survey was carried out in loops tied to a chained and levelled base-line which extended over twenty miles along the Salmon glacier and adjoining snowfields with stations every $600 \mathrm{ft}$. As the firn line receded, severe crevassing made the work difficult and a survey was carried out using two transits located on adjacent mountains, controlled by a system of visual signals. The survey was accurate to about $2 \mathrm{ft}$. in $10,000 \mathrm{ft}$.

Absolute movement of the glacier surface was determined from the movement of stakes and was of the order of $8 \mathrm{in}$. a day. Samples of ice at various depths down to $80 \mathrm{ft}$. were collected for an analysis of their tritium content. Mr. G. Falconer (University of 'Toronto) also carried out geomorphological studies. The rest of the party was made up of graduates and undergraduates from the Universities of British Columbia and Toronto. The results of the various projects are being prepared and will be published in detail later. A second expedition is planned for the summer of 1957 , to extend the present investigations and also to undertake other glaciological studies, including micro-meteorology.

\section{THE RADIO RESEARCH STATION REPORT FOR 1955}

$\mathrm{T}$ HE Radio Research Organization of the Department of Scientific and Industrial Research has for many years past been the main centre of research in Britain on the propagation of radio waves; and both civilian and defence users of telecommunications look to the Radio Research Station increasingly for advice. The work is not, however, confined to the study of propagation, and during recent years atten. tion has been given to investigations of materials used in radio components and equipment, and to the development of accurate methods of measuring power and field-strength at increasingly high frequencies. The report on this and the related work carried out during the calendar year 1955* comprises a general review made by the Radio Research Board, signed

* Department of Scientific and Industrial Research. Report of the Radio Research Board with the Report of the Director of Radio Research for the Year
1956.) 38. 6 d. net. by the chairman, Sir Noel Ashbridge, together with a more detailed report on the work by Dr. R. L. Smith-Rose, director of radio research in the Department of Scientific and Industrial Research.

The report describes, with the aid of a plan, the new building which has been under construction at the Radio Research Station, Ditton Park, Slough, and has been occupied during the present year. 'Ihis provides improved facilities for research and development of the laboratory type, while retaining some two hundred acres of agricultural land for field work. In addition to this central establishment, the organ. ization maintains other observatories for measurements on the ionosphere and on atmospheric noise at Inverness, Singapore and at Port Stanley in the Falkland Islands. The latter station also works in close co-operation with a similar observatory at Port Lockroy, Graham Land, which is staffed by tho Falkland Islands Dependencies Survey. Some of the work on wave propagation and alse on the properties of materials is carried out, by contract arrangements or otherwise, with various research workers at University College, Ibadan, and with university groups at Cambridge, Edinburgh, London, Manchester and Swansea.

Research on wave propagation. 'The work conducted on radio wave propagation has been extended over a very wide range of frequencies, from about $10 \mathrm{kc} . / \mathrm{s}$. to several thousand megacycles per second. At the low-frequency end of the range, investigations are being conducted into the time and space variations of the phase and amplitude of the field received from a transmitter, since a detailed knowledge of these is essential to the development and full exploitation of long-distance radio navigational aids. At the other end of the spectrum, from a few hundred to several thousand megacycles per second, much research is in progress on the propagation of waves along the ground and through the lower atmosphere. 'This work is of great importance in connexion with the development of television, and also in view of the realization that the scattering of radio waves by turbulent portions of the troposphere has a practical application to communication by very short waves over distances well beyond the normal horizon. Intermediate between these extremes, the transmission of high-frequency waves (3-30 Mc./s.) by way of the ionosphere is still being actively pursued. Progress has been made in the use of the back-scatter technique in this connexion, whereby radio waves are returned from a distant point by scattering from the ground, having undergone reflexion at the ionosphere on both the outward and return journeys. During the year under review, it was found that, in the winter months, echoes were received which apparently corresponded to long hops much greater than the usual maximum of $4,000 \mathrm{~km}$. for a single-hop reflexion from the ionosphere. With the view of exploring this and some associated phenomena, preparations are well advanced for the experimental comparison of this type of back-scatter with the measurement of the field-strength of signals from radio transmitters at various distances along the same great-circle path.

Research on materials. The behaviour of germanium in the form of rectangular monocrystalline filaments and in the form of commercial diodes and transistors has received a great deal of attention at the Radio Research Station. The noise characteristics of germanium are of particular interest ; and observations have been made of the spectral density of noise 